\title{
The Effects of Orientation, Window Size, and Lighting Control to Climate-Based Daylight Performance and Lighting Energy Demand on Buildings in Tropical Area
}

\author{
Randy Frans Fela ${ }^{1}$, Sentagi Sesotya Utami ${ }^{1}$, Rizki Armanto Mangkuto ${ }^{2}$, Dwi Joko Suroso ${ }^{1}$ \\ ${ }^{1}$ Department of Nuclear Engineering and Engineering Physics, Faculty of Engineering, Universitas \\ Gadjah Mada, Yogyakarta, Indonesia \\ ${ }^{2}$ Building Physics Research Group, Faculty of Industrial Technology, Institut Teknologi Bandung, \\ Bandung, Indonesia
}

\begin{abstract}
The use of daylight offers a positive contribution to building energy savings yet also provoke a shortfall anticipation such as the large amount of light and visual discomfort. Moreover, building energy demand will also depend on the lighting control system combined with occupants' behaviour of which is still rarely studied. This paper addressed the evaluation of climate-based daylight performance in a simulated reference office with a single unglazed opening measuring various window-to-wall ratio on one of the short façades facing different orientations. Modelling and simulation were performed in Radiance and Daysim using weather data of Yogyakarta and Bandung, Indonesia. Six different lighting control conditions were included. The following metrics observed are: average daylight factor, spatial daylight autonomy, spatial useful daylight illuminance, simplified daylight glare probability and lighting energy demand due to the lighting control system. Sensitivity analysis using multiple linear regression was also included. Excluding the average daylight factor, the results yielded similar trends for each metrics in two cities. However, the trend of sDA and sUDI-e in Yogyakarta are getting higher than Bandung in contrast with lighting energy demand. Moreover, combination switch-off occupancy \& dimming system shows the most efficient lighting control system in all conditions.
\end{abstract}

\section{Introduction}

The use of daylight in building design can provide positive improvement i.e. energy savings or in contrary the negative effects i.e. boosting thermal cooling load and the energy needs. The large amount of light, its quality and uncontrolled glare can also provoke visual discomfort of building occupants. To overcome this issue, several daylight metrics have been recommended by previous studies. It can be using the well-recognized daylight factor (Moon, P. and Spencer, D.E. 1942; R.G. Hopkinson et al., 1966; A.C Stevenson, 1937) and some extensive metrics based on climate perspective i.e. daylight autonomy (Illuminating Engineering Society (IES). LM83-12, 2012) and useful daylight illuminance (UDI) (Nabil A and Mardaljevic J, 2005; 2006). As an undesired impact of harvesting sunlight into the building, glare effect is also considered to estimate in a daylit space. It is therefore the metrics for estimate daylight glare probability is also included in some literatures (Jakubiec, J.A and Reinhart, C.F, 2011).

The exploration of daylight optimization by evaluating climate-based daylight metrics as an effect of modification of façade orientation, ratio between window and wall surface area facing certain orientation has been massively studied (Arimi F, 1977; Johnson R, et al., 1984; Johnson R et al., 1985). A lot of work can also be found corresponding to this topic. However, it is noticed that most studies on this territory were carried out in subtropical area (Inanici M.N and Demirbilek F.N, 2000; Goia F et al., 2013; Ochoa C.E et al, 2012; Lartigue B et al., 2014; Futrell B.J et al, 2015; Shen H and Tzempelikos A, 2013). Although there are several previous related works conducted in tropics, a number is still less attention and the output variables are approximately similar (Linhart F et al., 2010; Ermonds I.R and Greenup P.J, 2002; Rahim R et al, 2004; Janjai $\mathrm{S}$ et al, 2013). Moreover, the specific effect of energy consumption due to the lighting control system which combines participatory of occupants are rarely studied, in particular for tropical area (Theodorson J, 2014; Mangkuto R.A et al., 2016; Vanhoutteghem L et al, 2015).

It is therefore, this study reports the effect of window size (window-to-wall ratio), its orientation and lighting control system to the climate-based daylight performance. Daylight metrics including daylight factor (DF), daylight autonomy (DA), useful daylight illuminance (UDI), and daylight glare probability (DGP) were carried out in this study. Spatial distribution (discrete number) of the results from sensors were undertaken. Limitation and modified threshold to capture effective numbers of metric results were determined. In particular, the effect of active and passive combination for lighting control system was also investigated.

\section{Methods}

A case study is a reference office with inner space of $6 \mathrm{~m}$ x $4 \mathrm{~m}$ x $3 \mathrm{~m}$ (as proposed by van Dijk and Platzer, 2003) and a single unglazed opening measuring various window-to-wall ratio $(10 \%, 30 \%, 50 \%, 70 \%)$ on one of the short façades facing different orientation (East, North, South, West). Opening is always positioned in the central of the wall. The building was modelled in Radiance and simulated in Daysim 3.1e to perform daylight analysis 
over a year, using $0.5 \mathrm{~m}$ grid resolution and 5 min time step. The reflectance for wall, ceiling and floor was 0.7, 0.35 , and 0.35 respectively and kept constant during the simulation.

A comparative study of several lighting simulation softwares reported by Acosta I et al., (2015) found that the erroneous results generated by Daysim 3.1 is very acceptable compared to another programs. Unglazed roof and façade opening models were tested on the study and concluded that except on the odd occasion, Daysim 3.1 has a high precision.

The site locations were set for Yogyakarta $\left(7^{\circ} 47^{\prime} 49.4^{\prime} \mathrm{S}\right.$, $110^{\circ} 22^{\prime} 13.90^{\prime \prime}$ E) and Bandung (6 $54^{\circ} 53.07^{\prime \prime} \mathrm{S}$, $\left.107^{\circ} 36^{\prime} 35.3^{\prime \prime} \mathrm{E}\right)$, Indonesia. Yogyakarta is located near the southern coast of Java Island, surrounded by the province of Central Java and Indian Ocean on the south side. The city is categorized as tropical monsoon climate region (Am) according to Köppen-Geiger climate classification and located at an elevation of $128 \mathrm{~m}$ above sea level. Bandung is categorized as tropical rainforest region (Af) and located at an elevation of around $768 \mathrm{~m}$ above sea level. It is lying on a river basin surrounded by high Late Tertiary and Quaternary volcanic terrain (Climate-Data.org, 2018).

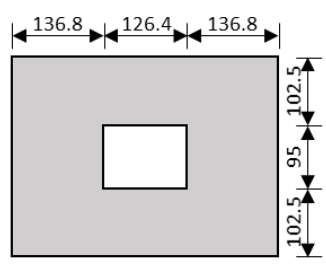

(a)

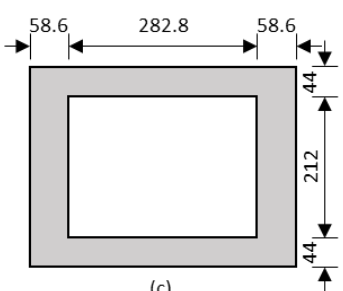

(c)

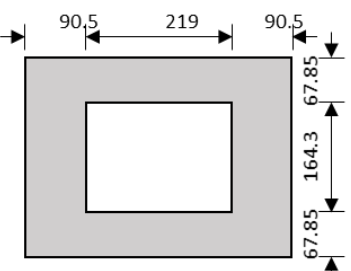

(b)

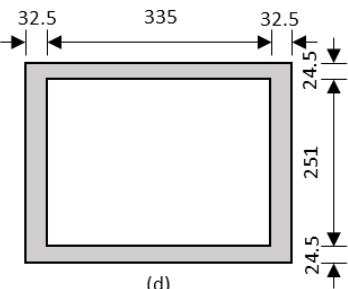

Figure 1: Elevation view of façade dimension [cm] with WWR of (a) 10\%, (b) 30\%, (c) 50\%, and (d) $70 \%$ (

\section{CBD performance}

In order to assess the building performance over daylight condition, several climate-based daylight metrics were evaluated as the result from simulation:

1. Daylight factor $\left(\mathrm{DF}_{\mathrm{av},>2 \%}\right)$, which is a percentage of spatially distributed daylight factor (DF) detected by sensors at specific position which having the value $>2 \%$. Daylight factor itself is a well-known parameter of which represents the ratio between indoors $\left(E_{\text {int }}\right)$ and outdoors $\left(E_{\text {ext }}\right)$ illuminance available on the workplane. In this case, the sensors are located along the centre position facing the window with $0.75 \mathrm{~m}$ height.

$$
\mathrm{DF}=\frac{E_{\text {int }}}{E_{\text {ext }}} \times 100 \%
$$

2. Spatial daylight autonomy $\left(\mathrm{sDA}_{300 / 50 \%}\right)$, which demonstrates a percentage of floor area or workplane that receives of at least DA 300 lx for at least $50 \%$ of the annual occupied time $T$ (IES, 2013). Consider that $\mathrm{DA}_{300}$ is formulated by (2) and $\mathrm{SDA}_{300 / 50 \%}$ is a ratio of area of which in practice, is approximated by number of sensors $(n)$ in certain positions of area $A$, hence the equation for $\mathrm{sDA}_{300 / 50 \%}$ is expressed in (3).

$$
\mathrm{DA}_{300}=\frac{t_{E \geq 300 l x}}{T} \times 100 \%
$$

and

$$
\mathrm{DA}_{300 / 50 \%} \approx \frac{n_{D A_{300} \geq 50 \%}}{n_{\text {total }}} \times 100 \%
$$

Continuous daylight autonomy (cDA) was also included to provide fraction of occupied hours per year where the illuminance at a point is greater than or equal to a target threshold value. Additionally, partial credit is given where the illuminance is less than the threshold value. It has a mutual relationship with a control system that dims the electric lighting (Ai, 2016). In conjunction with the continuous DA, the maximum DA was also assessed in this study which represents a condition where illuminance is ten times higher than threshold value. Hence, this is carried out to observe possible glare condition.

3. Spatial useful daylight illuminance (sUDI-a $50 \%$ and sUDI- $\mathrm{e}_{50 \%}$ ), which represents a ratio between floor area or workplane that having useful daylight autonomy within defined range of illuminance i.e. 100 2000lx (sUDI $100 \sim 2000$ or sUDI-a) and >2000 lx (sUDI $>2000$ or sUDI-e). Temporal threshold of $50 \%$ is included to provide more adequate analysis as initially proposed by literature (Mangkuto R.A et al., 2016). Consider the same approach with SDA that the amount of UDI could be approached by a number of sensors in area or space, so that:

$$
\begin{gathered}
\text { sUDI }-\mathrm{a}_{50 \%}=\frac{n_{U D I_{100-2000} \geq 50 \%}}{n_{\text {total }}} \times 100 \% \\
\text { sUDI }-\mathrm{e}_{50 \%}=\frac{n_{U D I_{>2000} \geq 50 \%}}{n_{\text {total }}} \times 100 \%
\end{gathered}
$$

It should be noted that the use of sUDI metric is an additionally proposed by the authors and therefore there is no standards available.

In later publications, UDI > $2000 \mathrm{~lx}$ was changed to UDI > $30001 \mathrm{x}$ by means to detect the likely appearance of glare. However, several findings from the study in tropics suggested that building occupants in the tropics may be more sensitive to discomfort glare and high illuminance values from daylight, so that smaller value for the upper threshold shall be preferred (Hirning et al., 2013; 2014; Mangkuto et al., 2016; 2017).

4. Simplified daylight glare probability, which is the simplified model from the authentic one that represents the percentage of occupied times all over the year which the simplified daylight glare probability (DGPs) at certain number of points exceeds 0.35. This model explained can be intensively found in (Wienold and Christoffersen, 2006, 2005) and also has been successfully applied in (Mangkuto et al., 2016). 


$$
\begin{aligned}
\mathrm{DGP} & =5.87 \times 10^{-5} E_{v} \\
& +0.0918 \log \left[1+\sum_{i=1}^{n}\left(\frac{L_{s, i}^{2} \omega_{s, i}}{E_{v}^{1.87} P_{i}^{2}}\right)\right]+0.016
\end{aligned}
$$

Where $E_{v}$ is the vertical eye illuminance from the light source [1x]; $L_{s}$ is the luminance of the source $\left[\mathrm{cd} / \mathrm{m}^{2}\right] ; \omega_{s}$ is the solid angle of the source seen by the observer; and $P$ is the position index which represents the change in perceived discomfort glare relative to the angular displacement of the source from observer's line of sight. The model proposed by (Wienold and Christoffersen, 2005) neglects the logarithmic part depending on the luminance and solid angle of the source seen, so that:

$$
\text { DGPs }=6.22 \times 10^{-5} E_{v}+0.184
$$

The $E_{v}$ was evaluated for the sensors positioned at $1.5 \mathrm{~m}$ height in the central point along facing the window.

5. Lighting energy demand per year $\left[\mathrm{kWh} / \mathrm{m}^{2}\right]$, which is the annual energy demand predicted due to the use of electric lighting to satisfy target illuminance in the investigated lighting zone.

\section{Simulation settings}

Daysim 3.1e was operated to perform daylight simulation. Parameters set up before the simulation begin is shown in Table I.

Table 1: Parameter setup for Daysim.

\begin{tabular}{|l|c|}
\hline \multicolumn{1}{|c|}{ Parameters } & Value \\
\hline Ambient bounces (ab) & 7 \\
\hline Ambient divisions (ad) & 1500 \\
\hline Ambient super-samples (as) & 100 \\
\hline Ambient resolutions (ar) & 300 \\
\hline Ambient accuracy (aa) & 0.1 \\
\hline Limit reflection (lr) & 6 \\
\hline Specular threshold (st) & 0.15 \\
\hline Specular jitter (sj) & 1 \\
\hline Limit weight (lw) & 0.004 \\
\hline Direct jitter (dj) & 0 \\
\hline Direct sampling (ds) & 0.2 \\
\hline Direct relay (dr) & 2 \\
\hline Direct pretest density (dp) & 512 \\
\hline
\end{tabular}

The zone is continuously occupied Monday through Friday from 8:00 to 17:00. The total annual hours of occupancy at the work place are 2349 hours. Thus, it represents a total of 261 working days during nine hours (08.00 17.00) per day. The electric lighting is activated 2370.8 hours per year which is calculated according to Lightswitch-2002 model (Reinhart, 2004). As referred to Pigg et al. (1996), the model assumes "switch-off probabilities for different times of user absence for a lighting system without controls, with an occupancy sensor". The model proposed by Reinhart (2004) considered different schemes of occupancy and lighting usage algorithm. In such models, for instance, there are switch-off delay time of around 10 minutes for occupancy sensor which accumulated the total hours of electric lighting is somewhat longer.
A number of different lighting control condition was simulated in this case i.e. 1) manual on/off switch near the door, 2) switch off occupancy sensor, 3) switch on/off occupancy sensor, 4) Photosensor controlled dimming system, 5) combination switch-off occupancy \& dimming system, and 6) combination on/off occupancy \& dimming system. In principle, two types of active and passive user behaviour are provided in Lightswitch model. In this case, equal mix of active and passive user behaviour in which both type of users will be equally distributed throughout the building was assumed for all lighting control conditions. The active blind control was applied which means user avoids direct sunlight on workplane.

The occupant performs a task that requires a minimum illuminance level of 300 lux. As mentioned by (Lo Verso et al., 2017), the installed lighting power density (LPD) for requirement illuminance $300 \mathrm{~lx}$ on the workplane is 7.25 W/unit area. In some conditions needed, the dimming system has an ideally commissioned photocell control with a ballast loss factor of 0.00 percent. The lighting system has a total standby power of $0.00 \mathrm{~W}$ per unit area. General definition of lighting control algorithm according to the Lightswitch-2002 model by Reinhart (2004) was applied. The office has no external nor internal shading device system installed.

\section{Sensitivity Analysis}

Assuming a linear relationship between output variables $y_{i}$ and any input variables $x_{i}$ containing $p$-vector, multiple linear regression was performed in this case towards sensitivity analysis. Suppose a computer model has inputs $x_{1}, \ldots, x_{k}$ and output $\mathrm{Y}$, after constructing and runs of the computer model, the multivariate observation $\left(x_{i 1}, \ldots, x_{i k}, Y_{i}\right) ; i=1, \ldots, n$ can be used to formulate an approximate regression model of the form,

$$
y_{j}=\beta_{0}+\beta_{1} x_{i 1}+\beta_{2} x_{i 2}+\cdots+\beta_{k} x_{i k}+\varepsilon_{i}
$$

Basically, standardizing all variables in the regression model can be used to eliminate the problems come up with different variables being measured in different units as the formula follows,

$$
\mathrm{X}^{*}=(X-\bar{X}) / s_{x}
$$

where $\bar{X}$ and $s_{x}$ is sample mean and standard deviation respectively. The formula (8) can be expressed in the matrix form as,

$$
\boldsymbol{Y}=\boldsymbol{X} \beta+\varepsilon
$$

Solving to determine $\beta$ which represents the standard regression coefficients (SRCs) that value the sensitivity of output variables as a function of input variables. Maximum value of SRC can be either 1, corresponds to positive influence of the input, or -1 corresponds to negative influence of the input.

\section{Results and Discussion}

\section{Trend analysis}

All graphics resulted from the simulation data are presented in Figure 2 to 7 as a function of window-to-wall ratio in all orientations in two cities. 


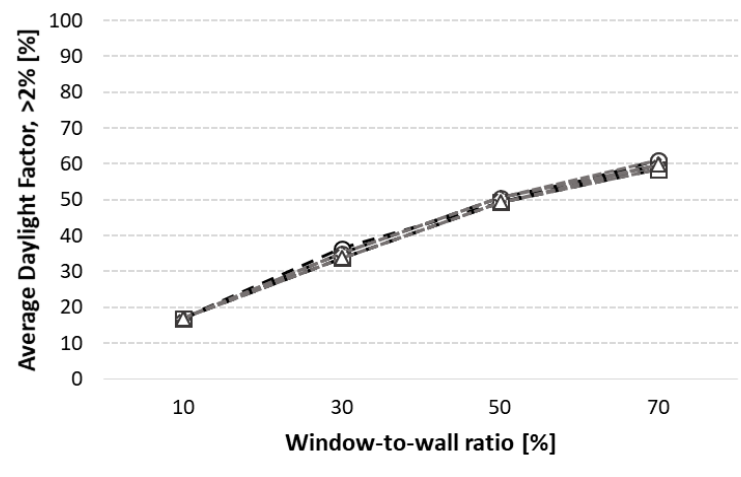

Figure 2: $D F_{a v}$ in all conditions.

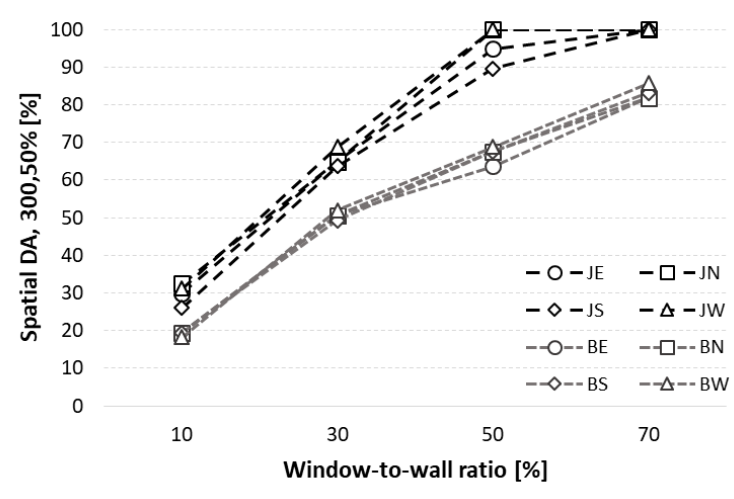

Figure 3: $s D A_{300 / 50 \%}$ in all conditions.

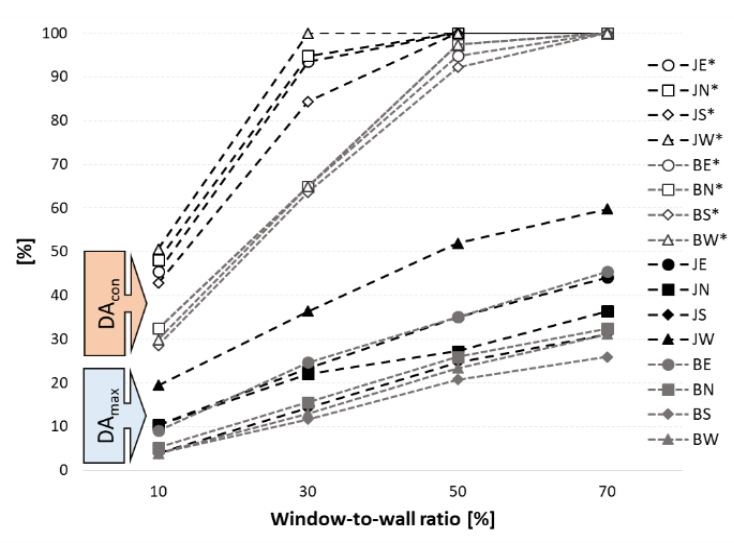

Figure 4: $c D A$ and $m D A$ in all conditions.

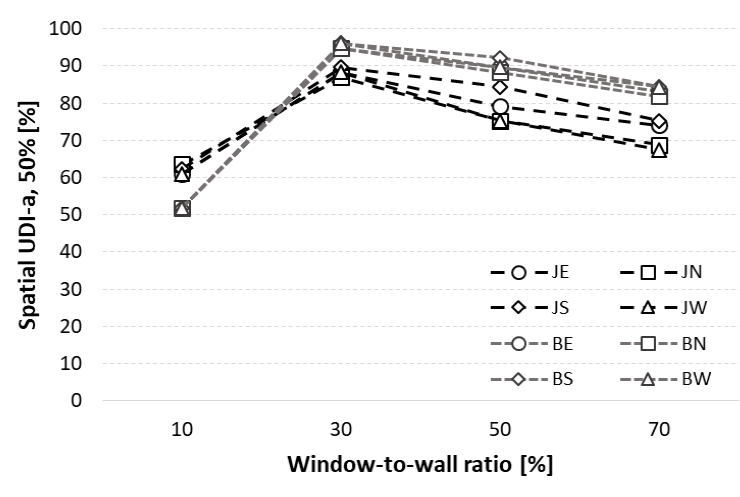

Figure 5: sUDI- $a, 50 \%$ in all conditions.

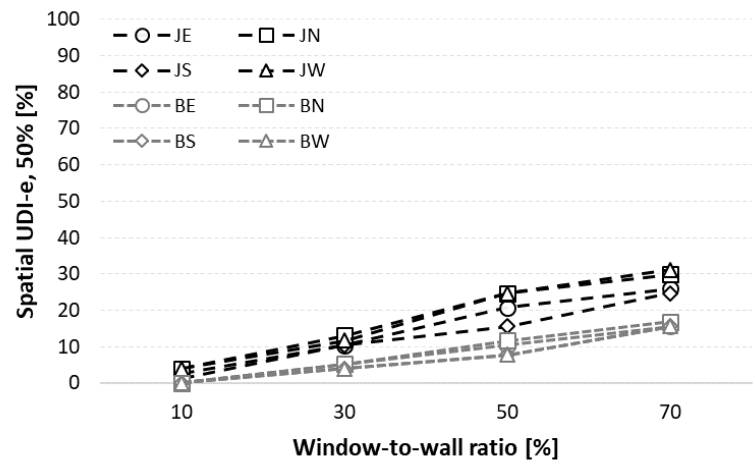

Figure 6: sUDI-e,50\% in all conditions.

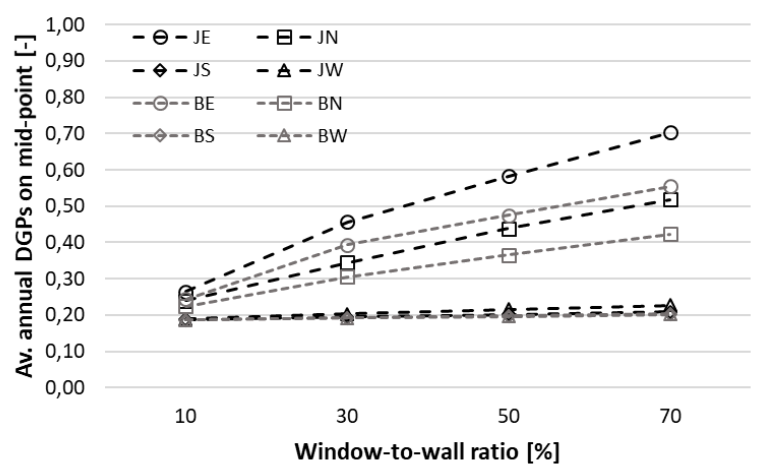

Figure 7: Average DGPs in all conditions.

The notation of " $\mathrm{J}$ " and " $\mathrm{B}$ " respectively refer to "Yogyakarta" and "Bandung". Meanwhile, the notation $\mathrm{E}, \mathrm{N}, \mathrm{S}$, and $\mathrm{W}$ each represents building orientations.

The daylight factor constantly changes over the orientation and geographical location (Figure 2). The percentage of minimum daylight factor $(2 \%)$ as agreed upon literatures significantly comes up in a linear trend over the glazing ratio for all orientations. It is because the effect of façade orientation is automatically negligible since the model is simulated under CIE overcast sky that is rotationally symmetrical. Averaging the number over all orientations, a coefficient of determination between DFav $_{>2} \%$ and window-to-wall ratio can be obtained both for Yogyakarta and Bandung $(R=0.985)$ as linear correlation is expressed in (8) and (9), respectively. It is noticeable that the relations between $\mathrm{DFav}_{>2} \%$ and WWR for two cities are insignificant difference. It is because these cities are located at the southern hemisphere. However, the result for different metrics might be dissimilar because of the geographical elevation of cities is not identical.

$$
\begin{aligned}
& y=14.351 x+4.3831 \\
& y=14.416 x+4.2208
\end{aligned}
$$

The different results are noticeable of the results for spatial daylight autonomy $\left(\mathrm{sDA}_{300 / 50 \%}\right)$ in two locations (Figure 3). Both graphical lines show insignificant difference between glazing-face directions, however, Yogyakarta has a higher $\mathrm{sDA}_{300 / 50 \%}$ than Bandung as the 
gap can be considered particularly in a condition of WWR50\%. Either in Yogyakarta or Bandung, a slope ( $\mathrm{sDA}_{300,50 \%}$ / window-to-wall ratio) declines or stable after WWR 50\%. In Yogyakarta, percentage of area that at least a half of total occupied time receives above the illuminance threshold approaching to $100 \%$. It means additional openings will accommodate an excessive amount of light which also lead negative impacts for comfort i.e. thermal and visual (glare), and so the energy consumption (i.e. cooling load).

Considering the partial credit for illuminance $<300 \mathrm{~lx}$ in continuous daylight autonomy (cDA) (Figure 4), the condition occurs more rapidly which is in WWR $30 \%$ and $50 \%$ individually for Yogyakarta and Bandung. This condition may occur due to the occurrence of direct sunlight in a daylit space. A patch of direct sunlight on a workplane will dispense greater illuminance than average. It can be investigated by measuring the occurrence of greatly higher daylight illuminance in space. It can be represented by maximum daylight autonomy (mDA). The threshold of mDA is 10 times higher than illuminance threshold (300 1x). In Figure 4, the highest percentage of $\mathrm{mDA}$ is increasingly exist for west-oriented building facade in Yogyakarta (19.48\% - 59.74\%) for all WWR variations. It is followed by east orientation and linearly increase at similar value for two cities. The geographical location for Indonesia that passed by equator naturally allows the sunlight appears from east to west during a day. Thus, the building surfaces facing on these directions obtain longer duration of sunlight exposures (assuming without a shading). That is, west and east orientation is not highly recommendable if direct sunlight is undesired. The remaining trends show similar line with a small difference.

Likewise, sUDI-a $50 \%$ and sUDI- $\mathrm{e}_{50 \%}$ of all orientations individually displays similar trend over the changes of window-to-wall ratio (Figure 5). The maximum sDA-a50\% occurs in WWR30\% after increasing significantly from WWR $10 \%$. It slightly decreases after the maximum point with small differences between different orientations in each city. Excluding WWR10\%, Bandung has higher sUDI-a $50 \%$ than Yogyakarta in contrast with sDA $300,50 \%$. This is because sUDI- $a_{50 \%}$ has a lower threshold and a wide range of illuminance than $\mathrm{sDA}_{300,50 \%}$. It can be estimated that a space in Bandung has much bigger low illuminance value in at least $50 \%$ of annual occupied hours. In contrary, Figure 6 keeps showing that sUDI-e $\mathrm{e}_{50 \%}$ in Yogyakarta is always higher than Bandung in all variations. It also makes sense to say that the more opening area will increase sUDI- $\mathrm{e}_{50 \%}$ value. North and west orientation commits the highest contribution for sUDI-e ${ }_{50 \%}$ in Yogyakarta while facing the opening to east orientation effects more increasingly in Bandung rather than west orientation. It also can be seen that by facing the openings into south always provides a minimum sUDI$\mathrm{e}_{50 \%}$ in all openings area.

According to the potential glare that may occur along with the changes of opening area and its orientation, the average annual daylight glare probability (avDGPs) was spatially quantified as the graphic is displayed in Figure
7. As seen, north and east opening arrangement provoke a higher probability for glare condition. If we consider that the maximum threshold is 0.35 (DGP $>0.35$ is not suggested), then WWR30 is the maximum ratio for north orientation for both locations. Although the output west and south orientated openings are very small and identical, it is intuitively contradictory, particularly for west orientation, since it has the highest mDA and sUDI$\mathrm{e}_{50 \%}$ which correlates positively with a high illuminance and potential glare effect. One the reasonable argument for this is because the DGPs was only measured by the sensors in the middle position along the line that facing the window, but the other metrics are averaged related illuminance in all sensor positions. Moreover, this case can be further studied in the upcoming evaluation. On the other hand, although mDA value in west orientation is crucial to be considered particularly WWR50\% and 70\%, the numbers are relatively small for sUDI-e $50 \%(<35 \%)$. Thus, the results for DGPs to these orientations is still notably acceptable.

In summary, evaluating graphical results of climate-based daylight metrics by descriptive approach yielded that for WWR $50 \%$, south orientation or west can be primarily recommended in this case.

\section{Lighting Energy Demand}

In this study, lighting energy demand because of different behavior of lighting control system inside the building is provided in Figure 8.

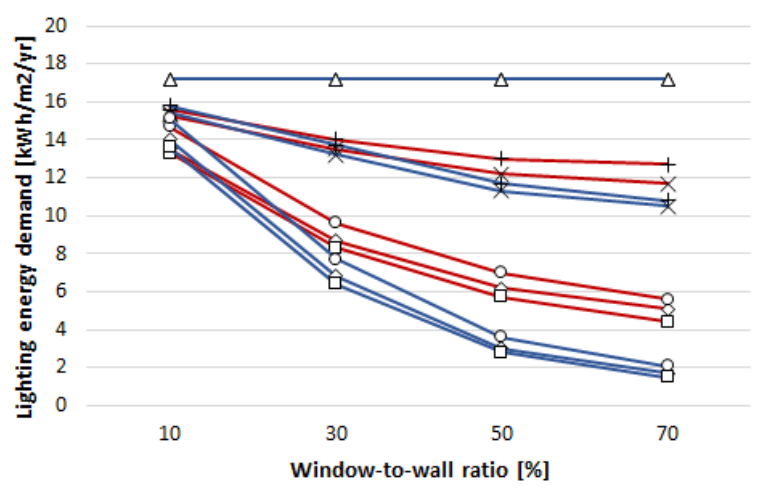

(a)

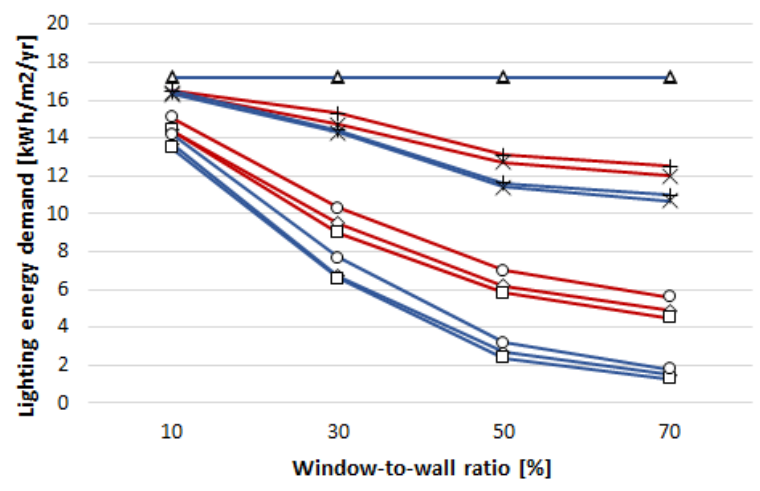

(b) 


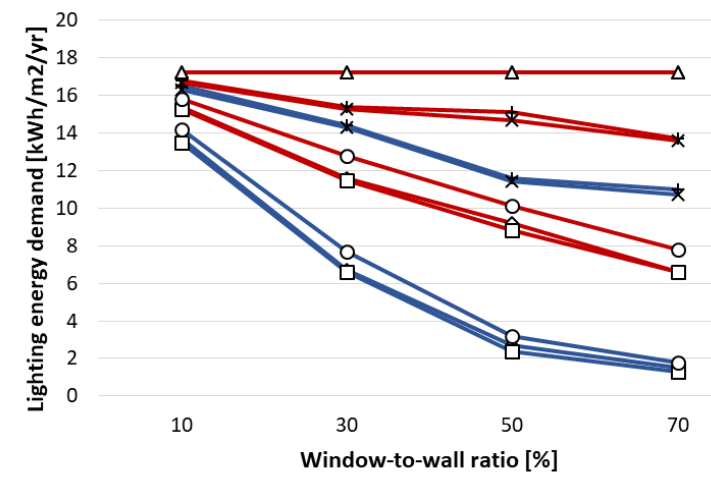

(c)

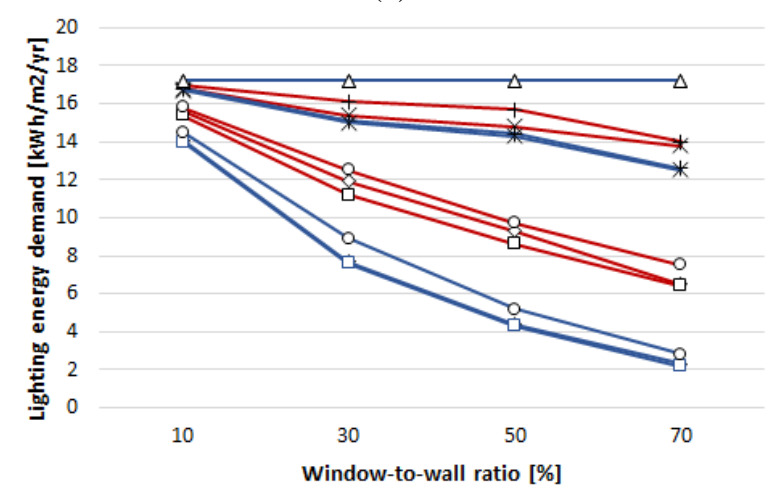

(d)

Figure 8: Lighting energy demand for each orientation (a) East, (b) North, (c) South, and (d) West in Yogyakarta (blue line) and Bandung (red line).

The type of lighting control system in Figure 8 is represented by symbol as follows,

1) (+) manual on/off switch near the door

2) (X) switch off occupancy sensor

3) $(\triangle)$ switch on/off occupancy sensor

4) $(\diamond)$ Photosensor controlled dimming system

5) () mixed switch-off occupancy \& dimming system

6) (o) mixed on/off occupancy \& dimming system

Overall, lighting energy demand is stable or decreases when the opening area increases. Building located in Bandung consumes larger electrical energy for lighting than Yogyakarta. In south-facing opening, the difference becomes significant for the same type of lighting control system. It may occur because the building receives the most effective sunlight on that direction (maximum sUDI$\mathrm{a}_{50 \%}$, minimum DGPs) so that the energy lighting control is under an optimum calculation in each location.

In tropical climate region, the context is somewhat unique and different compared to subtropics due to the relative position of the sun which is quite 'balanced' between north and south throughout a year, therefore it is presumably not accurate to obtain window orientation for optimum daylight performance by guessing. It is somehow different from subtropical climates where the sun's position tends to always be in the south (or north), so the optimum orientation is clear.

In Figure 8, lighting energy demand can reduces significantly by increasing area of openings since daylit space would receive higher amount of daylight. However, it indicates the rising of $\mathrm{UDI}_{>20001 x}$ and DGPs which is followed by visual discomfort due to glare and thermal cooling load. These parameters (UDI 20001x and DGPs) can be utilized as proxy to estimates acceptable visual glare, increasing temperature, cooling load and therefore cooling energy demand, and optimum WWR by objective and subjective measures within room observed. Note that the exact amount of cooling energy demand exclude the intention of this study.

In all conditions, switch on/off using occupancy sensor shows large energy consumption and generate same estimation for different location. This system is sometimes highly desirable either by users / occupants or building manager because it offers minimum efforts to lighting management. However, without adjusting the setting point periodically due to the changes of opening area, active hours, sensor-based number of occupancy or seasoning factor, the system will be energy wasteful.

Slightly better, switching on/off using electric button manually near the door or just applying switch off sensor can improve lighting energy demand. As a matter of choice, this could be easier to be implemented yet active participation of occupants is intensively expected. Lately contribution or indiscipline behavior consequently increases the lighting energy consumption.

The remaining is some suggestions for lighting control system during occupied hours. Switch-off occupancy arrangement combined with dimming system improves energy consumption into a lowest demand. A combination between on/off occupancy and dimming system or by controlling dimming system using photosensor is still higher to some degree. Alternatively, these schemes can be valuable when selectively deciding the lighting control system of buildings.

\section{Sensitivity analysis}

The standard regression coefficient (SRC) was evaluated for five performance indicators from all input variables as displayed in Figure 9.

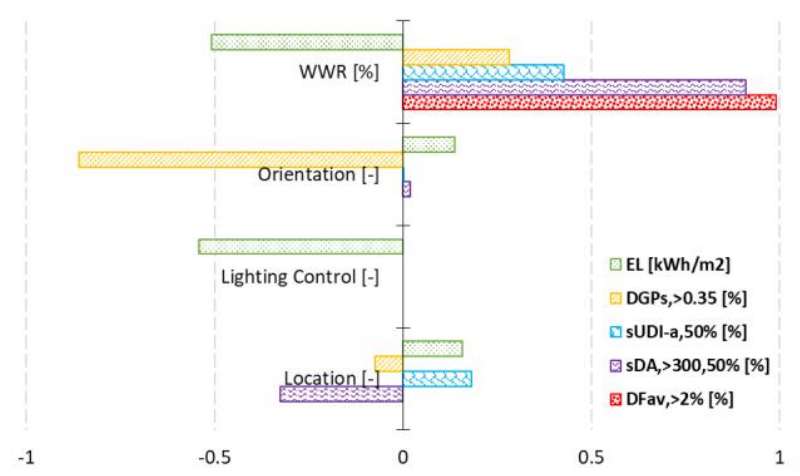

Figure 9: Standard regression coefficient for four input variables.

Generally, window-to-wall ratio is the most influential factors to all variables either in negative or positive agreement. Location and orientation are two moderate factors to all performance indicators. Lighting control exclusively dominates the energy demand. 
As window-to-wall ratio is a significant factor on CBD metrics and energy for lighting, daylight factor is the most dependent variable to WWR (SRC $=0.99)$. It is also influenced by the orientation but negligible. Building location and WWR both have an impact to $\mathrm{sDA}_{300 / 50 \%}$, sUDI-a $50 \%$, and DGPs $>0.35$. According to $\mathrm{sDA}_{300 / 50 \%}$, sUDI-a $50 \%$, modifying surface ratio between wall and opening has more meaningful effect to $\mathrm{sDA}_{300 / 50 \%}$ $\left(\mathrm{SRC}_{\mathrm{wwr}}=0.91, \quad \mathrm{SRC}_{\text {location }}=0.33\right)$ and $\mathrm{sUDI} \mathrm{a}_{50 \%}$ $\left(\mathrm{SRC}_{\mathrm{wwr}}=0.4, \mathrm{SRC}_{\text {location }}=0.18\right)$ than moving the location (has opposite effect for $\mathrm{sDA}_{300 / 50 \%}$ ). It means targeted value of these metrics can be achieved by modifying the opening ratio of building surface.

In contrary, DGPs is highly influenced by orientation $(\mathrm{SRC}=-0.86)$ and WWR $(\mathrm{SRC}=0.28)$. Different location has a small contribution to DGPs since the SRC is only 0.07. Lastly, lighting electric consumption is affected by all variations (lighting control, WWR, location and orientation). It can be intuitively predicted that lighting control and WWR are two dominant factors towards energy consumption of lighting since the standardized regression coefficient (SRC) is 0.54 and 0.51 respectively.

In terms of building design and performance for tropical humid area, in both cities, location selection has a small contribution to DGPs $>0.35$. Orientation plays an important role to DGPs $>0.35$. As can be seen in Figure 7, DGPs at south and west orientations are lower than north and east which is related to the climate condition within these area. Note that locations used in this study are located at southern hemisphere where Yogyakarta has a tropical monsoon climate and Bandung has tropical rainforest climate. During dry season (June to September) when total precipitation becomes very low (49 68 $\mathrm{mm}$ and 68 77 mm in Yogyakarta and Bandung and respectively), the north façade is exposed to direct sunlight. During the wet months (from October to May), average precipitation is much higher (136 392 $\mathrm{mm}$ in Yogyakarta and 83 291 $\mathrm{mm}$ in Bandung) thus reducing the total amount of direct sunlight in south façade (Climate-Data.org, 2018).

According to lighting energy demand and DGPs, window ratio to the wall has also a considerable contribution. The amount of DGPs due to building orientation can be compensated by varying percentage of WWR. However, although increasing WWR could increase CBD metrics and reduce lighting energy consumption, it would enlarge a thermal load of which lead to increase thermal energy demand. Different design strategies can be included to solve this condition such as implementing light shelf to prevent direct sunlight (Binarti F and Dewi S, 2016), and utilizing chromatic glazing technology as a filter of direct sunlight. Parametric design could also be an alternatives to obtain optimum design between CBD metrics, glare condition, and energy demand (Linhart F et al., 2010).

\section{Conclusion}

Simulation results show that daylight factor $\left(\mathrm{DFav}_{>2} \%\right)$, excluding for WWR, has a largely insignificant different for all variables. Most of results have similar trend for each WWR and façade orientation. In addition, building located in Yogyakarta obtains higher results of metrics ( $\mathrm{sDA}_{300 / 50 \%}$, cDA, mDA, sUDI-a $50 \%$, avDGPs) than in Bandung, excluding for sUDI- $\mathrm{e}_{50 \%}$. According to graphical results, building with WWR50\% with south orientation can be primarily recommended in this case as west orientation is following.

The integration between active and passive schemes for lighting control system yield that the maximum energy savings can be potentially achieved by combining switchoff occupancy \& dimming system. A combination between on/off occupancy and dimming system and by controlling dimming system using photosensor are the next alternatives.

Based on sensitivity analysis, WWR has a powerful positive contribution to daylight metrics, contradictory to energy demand. The ratio between opening and wall surface area is considerably no more than $50 \%$ in tropics. However, shading installation and selection of material used that still neglected in this study can also achieve different (or better) performance. Cost-effective factor as a part of financial efficient design is also suggested for future work to obtain whole optimum design. Concerning to energy efficiency, the selection of lighting control system and window to wall ratio are two primary issues as revealed in this study.

\section{Acknowledgement}

We gratefully acknowledge the funding from USAID through the SHERA program - Centre for Development of Sustainable Region (CDSR). In year 2017-2021 CDSR is led by Center for Energy Studies - UGM.

\section{References}

Acosta I, Muñoz C, Esquivias P, Moreno D, Navarro J. (2015). Analysis of the accuracy of the sky component calculation in daylighting simulation programs. Sol Energy 119: 54-67.

Ai, Q. (2016). The impact of overhang length, window orientation, and climate on spatial daylight autonomy (SDA) and annual sunlight exposure (ASE) for classroom. Thesis. The Pensylvania State University. Pensylvania (USA).

Arimi F. (1977). Daylighting as a factor in optimizing the energy performance of buildings. Energy Build $1: 175-82$.

Binarti F, Dewi S. (2016). The Effectiveness of Light Shelf in Tropical Urban Context. Environmental and Climate Technologies. 18: 42-53.

Climate-Data.org. (2018). Climate: Indonesia. Accessed on 2 May 2019.

Edmonds IR, Greenup PJ. (2002). Daylighting in the tropics. Sol Energy 73:111-21.

Futrell BJ, Ozelkan EC, Brentrup D. (2015). Bi-objective optimization of building enclosure design for thermal and lighting performance. Build Environ 92:561-602.

Goia F, Haase M, Perino M. (2013). Optimizing the configuration of a façade module for office buildings 
by means of integrated thermal and lighting simulations in a total energy perspective. Appl Energy 108:515-27.

Hopkinson RG, Petherbridge P, Longmore J. Daylighting. London: Heinemann; 1966.

Illuminating Engineering Society (IES). LM-83-12: approved method: IES spatial daylight autonomy $(s D A)$ and annual sunlight exposure (ASE). New York: Illuminating Engineering Society; 2013.

Inanici MN, Demirbilek FN. (2000). Thermal performance optimization of building aspect ratio and south window size in five cities having different climatic characteristics of Turkey. Build Environ $35: 41-52$.

Jakubiec JA., Reinhart, CF. (2012). The adaptive zone a concept for assessing discomfort glare throughout daylit spaces. Lighting Res. Technol 44:149-170.

Janjai S, Nunez M, Prathumsit J, Wattan R, Sabooding R. (2013). A semi-empirical approach for the estimation of global, direct and diffuse illuminance under clear sky condition in the tropics. Energy Build 66:177-82.

Johnson R, Sullivan R, Selkowitz SE, Nozaki S, Conner C, Arasteh D. (1984). Glazing energy performance and design optimization with daylighting. Energy Build 6:305-17.

Johnson R, Arasteh D, Selkowitz SE. Energy reduction implications with fenestration. In: Proceedings of CLIMA 2000, world congress on heating, ventilating, and air conditioning. Copenhagen, Denmark; August 26-29, 1985.

Lartigue B, Lasternas B, Loftness V. (2014). Multiobjective optimization of building envelope for energy consumption and daylight. Indoor Built Environ 23:70-80

Linhart F, Wittkopf SK, Scartezzini J-L. (2010). Performance of anidolic daylighting systems in tropical climates - parametric studies for identification of main influencing factors. Sol Energy 84:1085-94.

Lo Verso, V.R.M., Mihaylov, G., Pellegrino, A., Pellerey, F. (2017). Estimation of the daylight amount and the energy demand for lighting for the early design stages: Definition of a set of mathematical models. Energy and Buildings 155, 151-165.

Mangkuto, R.A., Rohmah, A.D., Asri, A.D. (2016). Design optimisation of window size, orientation, and wall reflectance with regard to various daylight metrics and lighting energy demand: A case study of buildings in the tropics. Applied Energy 164, 211-219.

Mangkuto, R.A., Kurnia, K.A., Azizah, D.N., Atmodipoero, R.T., Soelami, F.X.N. (2017). Determination of discomfort glare criteria for daylit space in Indonesia. Solar Energy 149, 151-163.
Moon P, Spencer DE. (1947). Illumination from a nonuniform sky. Illum Eng Society of New York 37:70726.

Nabil A, Mardaljevic J. (2005). Useful daylight illuminance: a new paradigm to access daylight in buildings. Light Res Technol 37:41-59.

Nabil A, Mardaljevic J. (2006). Useful daylight illuminances: a replacement for daylight factors. Energy Build 38:905-13

Ochoa CE, Aries MBC, van Loenen EJ, Hensen JLM. (2012). Considerations on design optimization criteria for windows providing low energy consumption and high visual comfort. Appl Energy 95:238-45.

Pigg, S., Eilers, M., Reed, J. (1996). Behavioral aspects of lighting and occupancy sensors in private offices: a case study of a university office building. Proceedings of the 1996 ACEEE Summer Study on Energy Efficiency in Buildings 8, 8.161-8.171.

Rahim R, Baharuddin, Mulyadi R. (2004). Classification of daylight and radiation data into three sky conditions by cloud ratio and sunshine duration. Energy Build 36:660-6.

Reinhart, C.F. (2004). Lightswitch-2002: a model for manual and automated control of electric lighting and blinds. Solar Energy 77, 15-28.

Shen H, Tzempelikos A. (2013). Sensitivity analysis on daylighting and energy performance of perimeter offices with automated shading. Build Environ 59:303-14.

Stevenson AC. (1937). On the construction of direct daylight factor diagrams with allowance for transmission losses through glass. J. Sci. Instrum $14: 231$

Theodorson J. (2014). Energy, daylighting and a role for interiors. J. Int Design 39[2]:37-56.

van Dijk, D., Platzer, W.J. (2003). Reference office for thermal, solar and lighting calculations, Report no. swift-wp3-tno-dvd-030416. International Energy Agency (IEA) Task 27.

Vanhoutteghem, V., Skarning, GCJ., Hviid, CA. (2015). Impact of facade window design on energy, daylighting and thermal comfort in nearly zero-energy houses. Energy and Build 102:149-156.

Wienold, J., Christoffersen J. (2005). Towards a new daylight glare rating. Proceedings of the 10th European Lighting Conference - Lux Europa 2005, Berlin (Germany), 19-21 September 2005.

Wienold, J., Christoffersen, J. (2006). Evaluation methods and development of a new glare prediction model for daylight environments with the use of CCD cameras. Energy and Buildings 38, 743-757. 